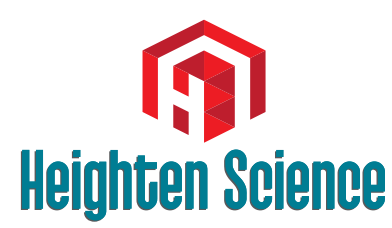

P U B L I C A T I O N S Corporation
*Address for Correspondence: Tao Zuo, Department of Medicine and Therapeutics, Institute of Digestive Disease, State Key Laboratory of Digestive Diseases, LKS Institute of Health Science, The Chinese University of Hong Kong, Hong Kong, China, Email:Tao.Zuo@cuhk.edu.hk

Submitted: 10 January 2018

Approved: 18 January 2018

Published: 19 January 2018

Copyright: @ 2018 Zuo T. This is an open access article distributed under the Creative Commons Attribution License, which permits unrestricted use, distribution, and reproduction in any medium, provided the original work is properly cited.
Editorial

\section{Unveiling the gut virome in human health and diseases}

\author{
Tao Zuo* \\ Department of Medicine and Therapeutics, Institute of Digestive Disease, State Key Laboratory \\ of Digestive Diseases, LKS Institute of Health Science, The Chinese University of Hong Kong, \\ Hong Kong, China
}

Due to the advances in high-throughput sequencing technologies, the gut vriome is increasingly being perceived as one important component of the gut microbiome, where the number of viral biological entities is believed to far outcompetes that of the bacterial populations [1,2]. The human virome are primarily composed of bacteriophages, animal-cell viruses, endogenous retroviruses and viruses causing persistent and latent infections. Collectively they contains a more diverse genetic entity than the gut bacteria $[3,4]$. While the composition of them in the gut is precipitately being revealed, their roles in human health remain largely unexplored. It is undeniable that certain gut viruses are deleterious to human health. Interestingly, enteric viruses however, in some cases, can recapitulate the beneficial effects of commensal bacteria through different mechanisms, including modulating the innate and adaptive immunity of the host [5-7].

A healthy human gut virome are predominanted by bacteriophages, temperate dsDNA Caudovirales and ssDNA Microviridae that latently infect their bacterial hosts and when under stress generate progenies that may infect and kill other bacteria [811]. In the absence of disease, gut bacteriophage exhibit significant diversity between individuals and are temporally stable $[8,10]$. Bacteriophages can adhere to host mucus providing a non-host-derived immunity, keeping gut bacteria in check [12]. Fecal microbiota transplantation (FMT) in Clostridium difficile infection has demonstrated that when more phage taxa were transferred from donor to recipient, a favourable treatment outcome was observed, and that donor fecal bacteriophage richness may be influential to treatment response [13], indicating the significance of gut phageome in human health. In addition, people are now realizing new therapeutics strategies complementary to antibiotics, using phages, though the results are still staggering [14].

A number of studies have shown gut viral dysbiosis in diseases $[2,15,16]$, particularly bacteriophages. Nonetheless, it remains unknown disease-specific alterations in the gut virome in a vast array of diseases. Alterations in bacteriophage composition might have impact on the bacterial microbiota ecology. Bacteriophages are primary drivers of bacterial fitness and diversity in different ecosystems [17]. Lysis of bacteria is associated with a release of lipids, nucleic acids, and proteins that serve as pathogenassociated molecular patterns (PAMPs) that trigger inflammatory responses to induce cytokines, cellular infiltration, and tissue damage. The gut microbiome are sensitive to bacteriophage invasion, leading to changes in the abundance of specific intestinal bacterial species [18]. In the gastrointestinal tract, bacteriophages are responsible for the horizontal transfer of genetic elements among bacterial populations, including those for antibiotic resistance and disease pathogenesis [18-20]. 
Human virome evolve rapidly due to varying conditions and stresses conferred by both the host and the environment [3,8,21-23]. Currently, we know little about the functions and roles of gut virobiota in human health and diseases, further experimental explorations of interactions of virobiota-host and virobiota-other components of the gut microbiota are warranted. Such studies hold the promise of yielding insightful understandings on the complex relationships between human physiology and the microbial communities, and hence lay the basis for devising new strategies for improving human health.

\section{References}

1. Virgin HW. The Virome in Mammalian Physiology and Disease. Cell. 2014; 157: 142-150. Ref.: https://goo.gl/YRtWsi

2. Carding SR, Davis N, Hoyles L. Review article: the human intestinal virome in health and disease. Aliment Pharmacol Ther. 2017; 46: 800-815. Ref.: https://goo.gl/k1dtxk

3. Ogilvie LA, Jones BV. The human gut virome: a multifaceted majority. Frontiers in Microbiology. 2015; 6: 918. Ref.: https://goo.gl/6imc97

4. Lecuit M, Eloit M. The human virome: new tools and concepts. Trends in Microbiology. 2013; 21: 510-515. Ref.: https://goo.gl/jf55PZ

5. Yang JY, Min-Soo Kim, Eugene Kim, JH Cheon, Yong-Soo Lee, et al. Enteric Viruses Ameliorate Gut Inflammation via Toll-like Receptor 3 and Toll-like Receptor 7-Mediated Interferon-beta Production. Immunity. 2016; 44: 889-900. Ref.: https://goo.gl/k5iWbW

6. Kernbauer $E$, Ding $Y$, Cadwell $K$. An enteric virus can replace the beneficial function of commensal bacteria. Nature. 2014; 516: 94-98. Ref.: https://goo.gl/kXfpXS

7. Duerkop BA, Hooper LV. Resident viruses and their interactions with the immune system. Nature Immunology. 2013; 14: 654-659. Ref.: https://goo.gl/H9DVVk

8. Minot S, Alexandra Bryson, Christel Chehoud, Gary D Wu, James D Lewis, et al. Rapid evolution of the human gut virome. Proceedings of the National Academy of Sciences of the United States of America. 2013; 110: 12450-12455. Ref.: https://goo.gl/JcxFHs

9. Minot S, Grunberg S, Wu GD, Lewis JD, Bushman FD. Hypervariable loci in the human gut virome. Proceedings of the National Academy of Sciences of the United States of America. 2012; 109: 39623966. Ref.: https://goo.gl/jCKA5j

10. Alejandro Reyes, Matthew Haynes, Nicole Hanson, Florent E Angly, Andrew C Heath, et al. Viruses in the faecal microbiota of monozygotic twins and their mothers. Nature. 2010; 466: 334-338. Ref.: https://goo.gl/Pzwc5G

11. Alison S Waller, Takuji Yamada, David M Kristensen, Jens Roat Kultima, Shinichi Sunagawa, et al. Classification and quantification of bacteriophage taxa in human gut metagenomes. Isme Journal. 2014; 8: 1391-1402. Ref.: https://goo.gl/pB4BUU

12. Jeremy J Barra, Rita Auroa, Mike Furlana, Katrine L Whitesona, Marcella L Erb, et al. Bacteriophage adhering to mucus provide a non-host-derived immunity. Proceedings of the National Academy of Sciences of the United States of America. 2013; 110: 10771-10776. Ref.: https://goo.gl/jjGzqY

13. Tao Zuo, Sunny H Wong, Long Yan K Lam, Rashid Lui, Kitty Cheung, et al. Bacteriophage Transfer during Fecal Microbiota Transplantation Is Associated with Treatment Response in Clostridium Difficile Infection. Gastroenterology. 2017. 152: 140-141. Ref.: https://goo.gl/UBx9w8

14. Torres-Barceló $\mathrm{C}$, Hochberg ME. Evolutionary rationale for phages as complements of antibiotics. Trends in microbiology. 2016; 24: 249-256. Ref.: https://goo.gl/XDeVVo

15. Jason M Norman, Scott A Handley, Megan T Baldridge, Lindsay Droit, Catherine Y Liu, et al. DiseaseSpecific Alterations in the Enteric Virome in Inflammatory Bowel Disease. Cell. 2015; 160: 447-460. Ref.: https://goo.gl/nkvXH3

16. Tao Zuo, Sunny H Wong, Kelvin Lam, Rashid Lui, Kitty Cheung, et al. Bacteriophage transfer during faecal microbiota transplantation in Clostridium difficile infection is associated with treatment outcome. Gut microbiota. 2017. Ref.: https://goo.gl/HwGQcN

17. Brussow H, Canchaya C, Hardt WD. Phages and the evolution of bacterial pathogens: From genomic rearrangements to lysogenic conversion. Microbiology and Molecular Biology Reviews. 2004; 68: 560-602. Ref.: https://goo.gl/bKXZ7r 
18. Reyes A, Wu M, Mc Nulty NP, Rohwer FL, Gordon Jl. Gnotobiotic mouse model of phage-bacterial host dynamics in the human gut. Proceedings of the National Academy of Sciences of the United States of America. 2013; 110: 20236-20241. Ref.: https://goo.gl/oNsj8Z

19. Zhang YF, LeJeune JT. Transduction of bla(CMY-2), tet(A), and tet(B) from Salmonella enterica subspecies enterica serovar Heidelberg to S-Typhimurium. Veterinary Microbiology. 2008; 129: 418425. Ref.: https://goo.gl/7NRAUM

20. Elisa Maiques, Carles Úbeda, Susana Campoy, Noelia Salvador, Íñigo Lasa, et al. beta-lactam antibiotics induce the SOS response and horizontal transfer of virulence factors in Staphylococcus aureus. Journal of Bacteriology. 2006; 188: 2726-2729. Ref.: https://goo.gl/5SgY4m

21. Kim MS, Bae JW. Spatial disturbances in altered mucosal and luminal gut viromes of diet-induced obese mice. Environmental Microbiology. 2016; 18: 1498-1510. Ref.: https://goo.gl/xFtXJB

22. Samuel Minot, Rohini Sinha, Jun Chen, Hongzhe Li, Sue A Keilbaugh, et al. The human gut virome: Inter-individual variation and dynamic response to diet. Genome Research. 2011; 21: 1616-1625. Ref.: https://goo.gl/kyvFBW

23. Efrem S Lim, Yanjiao Zhou, Guoyan Zhao, Irma K Bauer, Lindsay Droit, et al. Early life dynamics of the human gut virome and bacterial microbiome in infants. Nature Medicine. 2015; 21: 1228-1234. Ref.: https://goo.gl/g6enGj 